\title{
Characterization of Fusarium graminearum Isolates Resistant to Both Carbendazim and a New Fungicide JS399-19
}

\author{
Yu Chen and Ming-Guo Zhou
}

College of Plant Protection, Nanjing Agricultural University, Key Laboratory of Monitoring and Management of Crop Diseases and Pest Insects, Ministry of Agriculture, Nanjing 210095, China.

Accepted for publication 30 October 2008.

\begin{abstract}
Chen, Y., and Zhou, M.-G. 2009. Characterization of Fusarium graminearum isolates resistant to both carbendazim and a new fungicide JS39919. Phytopathology 99:441-446.

Fusarium head blight (FHB) of wheat and other cereals, caused mainly by Fusarium graminearum, is one of the most economically important diseases worldwide, especially in the United States and China. The benzimidazole fungicides, particularly carbendazim (MBC), have been consistently used during the period of wheat heading and flowering in areas with warm and moist weather to control FHB in China for over 30 years. The effectiveness of MBC, however, has been threatened by the emergence of resistant pathogen populations in the field. JS399-19 (experimental number; a.i. 2-cyano-3-amino-3-phenylancryic acetate) is a novel cyanoacrylate fungicide discovered and patented by the Jiangsu Branch of National Pesticide Research \& Development South Center of China. To evaluate the potential risk of resistance development in MBCresistant $F$. graminearum isolates to this new fungicide JS399-19, five isolates each of MBC-resistant or -sensitive, which were classified into three different sensitivity phenotypes, such as sensitive (S), moderately resistant (MR), and highly resistant (HR) to MBC, were selected to induce JS399-19-resistant mutants by selecting resistance on potato sucrose agar (PSA) plates amended with JS399-19 at $10 \mu \mathrm{g} / \mathrm{ml}$. In this way, a total of 24 JS399-19-resistant mutants were obtained from all tested MBC-resistant or -sensitive isolates. All 50 single-spore progenies of each of the resistant mutants could grow normally on PSA plates

40 days and when stored on PSA slants at $4^{\circ} \mathrm{C}$ for 60 days. The mycelial growth and conidial production capacity were decreased in $52.4 \%$ of the resistant mutants, indicating that a fitness cost was associated with JS39919-resistant phenotypes of $F$. graminearum isolates. However, most of the mutants resistant to both MBC and JS399-19 exhibited high sexual reproduction capacity and pathogenicity as their parental isolates. Nevertheless, the majority of these mutants possessed fitness levels comparable to their parents. The results on the efficacy of the two fungicides for controlling FHB incited by the fungicide-resistant mutants were generally consistent with those of the in vitro sensitivity tests. JS399-19 was effective in controlling FHB caused by MBC-resistant isolates under field conditions, while it was not effective in controlling FHB caused by isolates resistant to JS399-19 or those that were resistant to both MBC and JS399-19. Moreover, the efficacy of the mixture of MBC and JS399-19 was also significantly lower in controlling FHB caused by the isolates resistant to both MBC and JS399-19 than the efficacy against the disease caused by the sensitive isolates, the MBC-resistant isolates, or the JS39919-resistant isolates. The results suggest that JS399-19 possessed a high risk in development of resistance in MBC-resistant and -sensitive $F$. graminearum isolates, and this double resistance to both of these fungicides could presumable emerge and create a major problem since both these fungicides are extensively used in China. Therefore, careful use of JS399-19 should be followed to delay resistance development in natural populations of $F$. graminearum, avoid unexpected control failures, and sustain the usefulness of MBC and the new product JS399-19.
\end{abstract} amended with JS399-19 at $10 \mu \mathrm{g} / \mathrm{ml}$, indicating stability of resistance to this fungicide. Also, all of the resistant mutants maintained their resistance to JS399-19 and/or MBC through eight transfers on PSA plates for
Additional keywords: fungicide resistance, multi-drug resistance, phenotype, wheat scab.
Fusarium graminearum Schwade [teleomorph = Gibberella zeae (Schweinitz) Petch] is one of the main pathogens causing Fusarium head blight (FHB) on wheat and other cereals. FHB is one of the most economically important diseases worldwide, especially in the United States and China $(7,22)$, being responsible for extensive damage to wheat in humid and semihumid regions of the world (1). In China, FHB generally occurs in the middle and lower reaches of the Yangtze River, Huaihe River Valley, and the Eastern coastal region. However, an increase in the disease in the northern and western wheat growing areas of China has occurred in the last decade. FHB not only reduces grain yields by 5 to $15 \%$ in years of moderate epidemics and up to $40 \%$ in years of severe epidemics, but also causes decrease in grain quality because of contamination with mycotoxins (24), such as deoxynivalenol (DON, vomitoxin) $(25,26)$. These mycotoxins could inhibit amino acid incorporation and protein production in

Corresponding author: M.-G. Zhou; E-mail address: mgzhou@njau.edu.cn

doi:10.1094/PHYTO-99-4-0441

(C) 2009 The American Phytopathological Society plant tissues (5), and also, cause emesis and feed refusal in animals $(14,15)$.

To control FHB, fungicide sprays have been used during the last few decades because only few cultivars with effective resistance to this disease are available. The benzimidazole fungicides, particularly carbendazim (MBC), have been consistently used during the period of wheat heading and flowering in areas with warm and moist weather to control FHB in China for over 30 years (35). However, the effectiveness of $\mathrm{MBC}$ has been threatened by the emergence of resistant pathogen populations in the field (34). Continuous MBC resistance monitoring showed that the frequency of resistant isolates in some regions of China increased gradually, and the efficacy of MBC against $F$. graminearum decreased dramatically after 1998 (28). Essentially, the effectiveness of carbendazim decreased along with the increase of the frequency of resistant pathogen populations in the field (34). JS399-19 (development code number; a.i. 2-cyano-3amino-3-phenylancryic acetate) is a novel cyanoacrylate fungicide discovered and patented by the Jiangsu Branch of National Pesticide Research \& Development South Center (NPRDSC) of China. According to some previous studies, this new fungicide 
exhibits specific activity against fungal plant pathogens of the genus Fusarium in which it strongly interferes with mycelial growth (19). The efficacy of JS399-19 in controlling FHB used at a $562.5 \mathrm{~g}$ a.i. ha ${ }^{-1}$ rate was better than that of MBC applied at $750 \mathrm{~g}$ a.i. $\mathrm{ha}^{-1}$ in three field experiments where MBC was extensively used for 3 decades and disease control failures occurred (19).

Because this new fungicide has just been marketed in China, no information on the characteristics and interactions of the resistance to this and $\mathrm{MBC}$ in $F$. graminearum populations is available. Moreover, strategies to manage the resistance risk should be developed and implemented to avoid unexpected control failures and sustain the usefulness of this new product. The objectives of this study were to (i) recover JS399-19-resistant mutants in the laboratory from isolates resistant to MBC collected from the field to obtain isolates resistant to both MBC and JS399-19 fungicides; (ii) carry out an initial evaluation of the resistance risk of MBC and JS399-19 in F. graminearum by determining the stability of the double-resistance to MBC and JS399-19; (iii) study the biological properties of these isolates resistant to both $\mathrm{MBC}$ and JS399-19; and (iv) test the efficacy of the two fungicides in controlling FHB incited by the resistant isolates.

\section{MATERIALS AND METHODS}

Fungicides and media. Technical grade carbendazim (MBC) was provided by Shenyang Academy of Chemistry and Industry (Shenyang, China). The material was dissolved in $0.1 \mathrm{~mol} / \mathrm{liter}$ hydrochloric acid $(\mathrm{HCl})$ at $10 \mathrm{mg} / \mathrm{ml}$ and kept as a stock solution. Technical grade JS399-19 (95.5\%) was provided by NPRDSC and dissolved in methanol to 4 and $40 \mathrm{mg} / \mathrm{ml}$ for stock solutions. The MBC and JS399-19 stock solutions were added to autoclaved media that had cooled at 40 to $50^{\circ} \mathrm{C}$, and the $\mathrm{pH}$ was adjusted to 6.8 in all media, using $0.1 \mathrm{~mol} / \mathrm{liter} \mathrm{HCl}$.

Potato sucrose agar (PSA) was used for routine cultures and in tests for sensitivity to MBC and JS399-19 sensitivity. Carrot agar medium was used for inducing the fungus to produce perithecia (18). Mung bean broth (MBB, $50.0 \mathrm{~g}$ of mung bean per liter of distilled water) was prepared for conidia production. Water agar (WA; $1.8 \%$ agar) medium was used to recover single-spore isolates.

Fungal isolates and phenotypic characterization of carbendazim resistance. Wheat samples were collected from three commercial wheat fields, Tongzhou in Jiangsu Province, Jiaxing in Zhejiang Province, and Shanghai of China during harvest in 2004 and 2005. The wheat fields were separated from each other by more than $100 \mathrm{~km}$. In each field, several spikes with symptoms of FHB were randomly collected from a designated $5.0 \times 5.0 \mathrm{~m}^{2}$ area, air-dried, placed in paper envelopes, and stored at $-20^{\circ} \mathrm{C}$. A previous study determined that 100 sensitive isolates of $F$. graminearum could not grow on PSA medium amended with $1.4 \mu \mathrm{g}$ of $\mathrm{MBC} / \mathrm{ml}$, whereas resistant isolates grew normally at this concentration (34). Therefore, $1.4 \mu \mathrm{g}$ of $\mathrm{MBC} / \mathrm{ml}$ is used as the critical concentration for detecting in vitro resistant field isolates. One hundred and sixty-five monoconidial isolates were obtained and reassessed for MBC sensitivity by transferring 5-mm-diameter plugs from the leading edge of an actively growing colony to a series of PSA plates amended with $0,0.5,1.4,50$, and $100 \mu \mathrm{g}$ of $\mathrm{MBC} / \mathrm{ml}$ and incubating at $25^{\circ} \mathrm{C}$ for 3 days. The isolates were classified as sensitive (S), moderately resistant (MR), and highly resistant (HR) based on their growth at the various concentrations of MBC as described previously (31). Five isolates (2021 [S], S21 [S], R03 [MR], 2052 [MR], and JT04 [HR]) were selected for the later studies (details below). Among these five selected isolates, S21 and R03 were confirmed to be vegetatively compatible in a previous study (9).

Seeds/cultivars. Yangmai56 is a local planted wheat cultivar sensitive to FHB. The seeds were used for perithecium production test and the spikes of the cultivars were used for pathogenicity tests of $F$. graminearum (details below).

Recovery of JS399-19-resistant mutants. Two hundred fresh mycelial plugs from the colony margins of each of the five selected isolates were transferred to each of the 50 PSA plates amended with $10 \mu \mathrm{g}$ of JS399-19 per $\mathrm{ml}$ and incubated in a growth chamber. Any spontaneous and fast-growing sectors from the otherwise restricted colonies on PSA plates were picked up for resistance identification on PSA plates and amended with $10 \mu \mathrm{g}$ of JS399-19 per ml. For the stable JS399-19-resistant mutants, single-spore isolates were established. The number of resistant mutants was counted. Autoclaved PSA was amended with JS399-19 to obtain final concentrations of 12.5, 25, 50, 100, 200 , and $400 \mu \mathrm{g} / \mathrm{ml}$, and the $50 \%$ effective concentration $\left(\mathrm{EC}_{50}\right)$ values of resistant mutants were calculated by regressing percentage growth inhibition against the $\log$ of fungicide concentration as described previously (19).

Stability of the double-resistance to carbendazim and JS399-19. Each recovered JS399-19-resistant mutant was selected randomly for each of the five parental isolates and 50 single-spore isolates established as mycelial cultures. Each of the latter was transferred to PSA plates containing $10 \mu \mathrm{g}$ of JS399-19 per ml of medium. In addition, all the resistant mutants and their parental isolates were transferred eight times onto new PSA plates with no fungicide by transferring single mycelial plugs to the new PSA plates (5-day culture for one time) for 40 days, or stored at $4{ }^{\circ} \mathrm{C}$ in the refrigerator for 60 days, and then the resistance to $\mathrm{MBC}$ and/or JS399-19 was determined again as described above to test for the resistance stability.

Biological properties of the isolates resistant to both $\mathrm{MBC}$ and JS399-19 (culture characterization, asexual and sexual reproduction ability, and pathogenicity). After culturing these isolates for 3 days on PSA, mycelial plugs ( $5 \mathrm{~mm}$ in diameter) of the isolates and their parental isolates were transferred to PSA plates at $25^{\circ} \mathrm{C}$ for 3 days. Colony diameter $(\mathrm{cm})$ was measured (with three PSA plates per isolate) to compare mycelial linear growth, and means were compared with Fisher's least significant difference (LSD) test. The growth of the aerial mycelium was also observed simultaneously.

After 3 days cultured on PSA, five mycelial plugs $(5 \mathrm{~mm}$ in diameter) of these special isolates and their parental isolates were transferred to each conical flask containing $100 \mathrm{ml}$ of MBB for preparing a shake culture for 7 days $\left(150 \mathrm{rpm}, 25^{\circ} \mathrm{C}, 12 \mathrm{~h}\right.$ photoperiod). There were three replicates for each of the special isolates and their parental isolates, and the tests were repeated twice. Sporulation capacity of the isolates was determined by counting the number of spores with a hemacytometer as described preciously (34). The conidial production of both resistant isolates and their parental isolates was compared using Fisher's LSD test.

To evaluate production of perithecia, autoclaved seeds of Yangmai56 wheat cultivar were inoculated with mycelial plugs ( $5 \mathrm{~mm}$ in diameter) of these resistant isolates and their parental isolates and incubated at $25^{\circ} \mathrm{C}$ for 7 days. Subsequently, the seeds were covered with sterile wet sands in petri plates (diameter $=$ $9 \mathrm{~cm})$ and incubated in a humid room $(\mathrm{RH}=80 \%)$ at $25^{\circ} \mathrm{C}$ and under light for $12 \mathrm{~h}$ daily. Production of perithecia was scored as ,+++++ , and + after 3 days incubation when the perithecia covered more than $2 / 3$, between $1 / 3$ and $2 / 3$, and less than $1 / 3$ of the grain area, respectively.

Winter wheat cultivar Yangmai56 was sown in fields located in Nanjing Agricultural University (Nanjing, China). A designated plot $\left(0.5 \times 0.5 \mathrm{~m}^{2}\right)$ including at least 40 wheat plants was chosen for each of the isolates. Each of the plots was separated by a $30-\mathrm{cm}$ interval with untreated wheat plants. First, conidial suspensions of each isolate were prepared in MBB and adjusted to a concentration of $10^{5}$ spores per $\mathrm{ml}$. Then, $10 \mu \mathrm{l}$ of conidia suspension of each isolate was injected into a flowering grain in the middle of the spike and at least 40 spikes were inoculated for 
All the JS399-19-resistant mutants, including those resistant to both MBC and JS399-19, and their parental isolates produced perithecia, and mature ascospores were observed after 2 weeks; however, their ability to produce perithecia seemed to have no direct relationship with resistance phenotype for the tested mutants (Table 2).

Mean values of FHB severity were compared 3 weeks after inoculation. There were no significant differences between the resistant mutants (JS399-19-resistant mutant and double-resistant isolates) and their parental isolates (Table 2). Therefore, the resistance to the two fungicides seemed not to affect the pathogenicity.

Efficacy of the two fungicides on FHB incited by resistant isolates. When no fungicide was applied, both the sensitive and the resistant isolates caused similar disease severity (no statistical difference) on wheat spikes. Moreover, no spikes with symptoms of FHB in the untreated wheat plants (including the plants in the $30-\mathrm{cm}$ intervals) and the wheat plants inoculated with autoclaved $\mathrm{MBB}$ and treated with water were found in the field. However, when JS399-19 was applied on the spikes after inoculation with $F$. graminearum isolates, all the selected sensitive isolates caused significantly lower disease severity than the selected resistant isolates. JS399-19 was effective in controlling FHB caused by MBC-resistant isolates under field conditions (Table 3), while it was not effective in controlling FHB caused either by the JS39919-resistant isolates or the isolates that were resistant to both MBC and JS399-19 (Table 3). Moreover, the efficacy of MBC+ JS399-19 was also significantly lower in controlling FHB caused by the isolates resistant to both MBC and JS399-19 than when the disease was caused by the sensitive, the MBC-resistant or the JS399-19-resistant isolates (Table 3).

\section{DISCUSSION}

Benzimidazole fungicides are site-specific fungicides that interfere with cell division. They bind to $\beta$-tubulin and affect microtubule function in many fungi $(4,13)$. Continuous $\mathrm{MBC}$ resistance monitoring showed that the frequency of resistant isolates in some regions of China increased gradually, and the efficacy of MBC against $F$. graminearum decreased dramatically after $1998(6,28)$. Resistant isolates could not be controlled by increasing the application rate or by shortening the spray interval and were fit and competitive in nature even without selective pressure (29). In a sense, the effectiveness of MBC was reduced due to the selection of a resistant pathogen population in the field (34).

JS399-19 was a novel fungicide that could strongly inhibit the mycelial growth of $F$. graminearum and exhibit an excellent efficacy in controlling FHB in field trial where control failures of MBC occurred (19). Management of benzimidazole resistance relies on reducing selection pressure by limiting exposure to these fungicides with the same mode of action, and using tank mixtures or replacement fungicides with different biochemical mode of action (15). In previous studies, it was reported that JS399-19 did exhibit strong fungicidal activity against $F$. graminearum and had the expected effect on limiting FHB occurrence in field trials at different sites (19). Furthermore, it also showed the ability to delay the development of MBC resistance in field trials where the control failures of carbendazim occurred (19). Additionally, the absence of cross-resistance between JS399-19 and other wellknown fungicides, such as MBC, tebuconazole, prochloraz, and azoxystrobin, suggested that the mode of action and resistance mechanism of JS399-19 may be unique and different from these fungicides (19). Thus, JS399-19 might presumably become the

TABLE 2. Comparison of characterization between resistant mutants and their parental strains of Fusarium graminearum

\begin{tabular}{|c|c|c|c|c|c|}
\hline Isolate $^{w}$ & Resistant phenotypes $^{\mathrm{x}}$ & $\begin{array}{l}\text { Mycelial linear } \\
\text { growth }(\mathrm{mm})\end{array}$ & $\begin{array}{l}\text { Sporulation capacity } \\
\left(10^{6} \mathrm{CFU} / \mathrm{ml}\right)\end{array}$ & $\begin{array}{c}\text { Fusarium head blight } \\
\text { severity }(\%)\end{array}$ & $\begin{array}{c}\text { Capacity to produce } \\
\text { perithecia }\end{array}$ \\
\hline 2021 & $\mathrm{C}^{\mathrm{S}} \mathrm{J}^{\mathrm{S}}$ & $67.3 \pm 2.9 \mathrm{a}^{\mathrm{y}}$ & $1.2 \pm 0.1 \mathrm{a}$ & $36.6 \pm 7.6 \mathrm{a}$ & $+++^{\mathrm{z}}$ \\
\hline $2021-1$ & $\mathrm{C}^{\mathrm{S} J \mathrm{R}}$ & $65.2 \pm 4.6 \mathrm{a}$ & $1.3 \pm 0.2 \mathrm{a}$ & $37.6 \pm 7.3 \mathrm{a}$ & +++ \\
\hline $2021-2$ & $\mathrm{C}^{\mathrm{S}} \mathrm{J}^{\mathrm{R}}$ & $54.2 \pm 3.2 \mathrm{~b}$ & $0.4 \pm 0.1 \mathrm{bc}$ & $37.6 \pm 8.3 \mathrm{a}$ & ++ \\
\hline $2021-3$ & $\mathrm{C}^{\mathrm{S}} \mathrm{J}^{\mathrm{R}}$ & $66.5 \pm 4.5 \mathrm{a}$ & $0.4 \pm 0.1 \mathrm{bc}$ & $34.5 \pm 9.4 \mathrm{a}$ & +++ \\
\hline $2021-4$ & $\mathrm{C}^{\mathrm{S}} \mathrm{J}^{\mathrm{R}}$ & $65.8 \pm 4.7 \mathrm{a}$ & $0.6 \pm 0.1 \mathrm{~b}$ & $35.9 \pm 6.7 \mathrm{a}$ & +++ \\
\hline $2021-5$ & $\mathrm{C}^{\mathrm{S} J \mathrm{R}}$ & $66.3 \pm 4.6 \mathrm{a}$ & $0.3 \pm 0.1 \mathrm{c}$ & $37.5 \pm 6.4 \mathrm{a}$ & +++ \\
\hline $2021-6$ & $\mathrm{C}^{\mathrm{S}} \mathrm{J}^{\mathrm{R}}$ & $51.6 \pm 4.5 b$ & $0.6 \pm 0.1 b$ & $38.7 \pm 6.7 \mathrm{a}$ & ++ \\
\hline $\mathrm{S} 21$ & $\mathrm{C}^{\mathrm{S}} \mathrm{J}^{\mathrm{R}}$ & $67.8 \pm 4.7 \mathrm{a}$ & $1.0 \pm 0.1 \mathrm{a}$ & $37.7 \pm 7.4 \mathrm{a}$ & +++ \\
\hline $\mathrm{S} 21-1$ & $\mathrm{C}^{\mathrm{S}} \mathrm{J}^{\mathrm{R}}$ & $65.5 \pm 5.4 \mathrm{a}$ & $0.7 \pm 0.1 b$ & $35.7 \pm 6.6 \mathrm{a}$ & ++ \\
\hline $\mathrm{S} 21-2$ & $\mathrm{C}^{\mathrm{S} J \mathrm{R}}$ & $64.9 \pm 3.1 \mathrm{a}$ & $0.6 \pm 0.1 \mathrm{c}$ & $37.2 \pm 7.4 \mathrm{a}$ & ++ \\
\hline $\mathrm{S} 21-3$ & $\mathrm{C}^{\mathrm{S}} \mathrm{J}^{\mathrm{R}}$ & $53.6 \pm 3.6 b$ & $0.8 \pm 0.1 \mathrm{~b}$ & $35.7 \pm 7.7 \mathrm{a}$ & ++ \\
\hline $\mathrm{S} 21-4$ & $\mathrm{C}^{\mathrm{S}} \mathrm{J}^{\mathrm{R}}$ & $65.0 \pm 4.6 \mathrm{a}$ & $0.8 \pm 0.1 \mathrm{~b}$ & $37.5 \pm 7.7 \mathrm{a}$ & ++ \\
\hline R03 & $\mathrm{C}^{\mathrm{HR}} \mathrm{J}^{\mathrm{S}}$ & $65.5 \pm 4.7 \mathrm{a}$ & $0.9 \pm 0.2 \mathrm{a}$ & $35.7 \pm 7.4 \mathrm{a}$ & ++ \\
\hline R03-1 & $\mathrm{C}^{\mathrm{HR}} \mathrm{JR}$ & $53.5 \pm 3.5 b$ & $0.6 \pm 0.2 b$ & $33.2 \pm 6.4 \mathrm{a}$ & +++ \\
\hline R03-2 & $\mathrm{C}^{\mathrm{HR}} \mathrm{J}^{\mathrm{R}}$ & $55.5 \pm 4.2 b$ & $0.3 \pm 0.1 \mathrm{c}$ & $36.9 \pm 7.9 \mathrm{a}$ & ++ \\
\hline R03-3 & $\mathrm{C}^{\mathrm{HR}} \mathrm{J}^{\mathrm{R}}$ & $56.4 \pm 3.4 b$ & $0.4 \pm 0.2 \mathrm{bc}$ & $36.7 \pm 6.1 \mathrm{a}$ & ++ \\
\hline R03-4 & $\mathrm{C}^{\mathrm{HR}} \mathrm{J}^{\mathrm{R}}$ & $64.2 \pm 3.6 \mathrm{a}$ & $0.4 \pm 0.1 \mathrm{bc}$ & $37.6 \pm 5.4 \mathrm{a}$ & ++ \\
\hline R03-5 & $\mathrm{C}^{\mathrm{HR}} \mathrm{JR}^{\mathrm{R}}$ & $54.7 \pm 4.3 b$ & $0.5 \pm 0.1 b$ & $34.6 \pm 6.5 \mathrm{a}$ & ++ \\
\hline 2052 & $\mathrm{C}^{\mathrm{MR} \mathrm{J}^{\mathrm{S}}}$ & $51.5 \pm 3.1 \mathrm{a}$ & $0.7 \pm 0.1 \mathrm{a}$ & $37.7 \pm 5.8 \mathrm{a}$ & + \\
\hline $2052-1$ & $\mathrm{C}^{\mathrm{MR} \mathrm{J}^{\mathrm{R}}}$ & $42.2 \pm 3.4 b$ & $0.3 \pm 0.0 \mathrm{c}$ & $32.5 \pm 6.5 \mathrm{a}$ & + \\
\hline $2052-2$ & $\mathrm{C}^{\mathrm{MR} \mathrm{J}^{\mathrm{R}}}$ & $40.2 \pm 3.6 b$ & $0.4 \pm 0.1 \mathrm{~b}$ & $38.5 \pm 6.5 \mathrm{a}$ & ++ \\
\hline $2052-3$ & $\mathrm{C}^{\mathrm{MR} J \mathrm{R}}$ & $41.5 \pm 2.8 b$ & $0.2 \pm 0.1 \mathrm{c}$ & $40.0 \pm 8.4 \mathrm{a}$ & + \\
\hline JT04 & $\mathrm{C}^{\mathrm{HR}} \mathrm{J}^{\mathrm{S}}$ & $67.4 \pm 5.4 \mathrm{a}$ & $0.6 \pm 0.1 \mathrm{a}$ & $37.4 \pm 6.6 \mathrm{a}$ & +++ \\
\hline JT04-1 & $\mathrm{C}^{\mathrm{HR}} \mathrm{J}^{\mathrm{R}}$ & $55.1 \pm 3.8 b$ & $0.3 \pm 0.0 \mathrm{c}$ & $38.4 \pm 6.4 \mathrm{a}$ & +++ \\
\hline JT04-2 & $\mathrm{C}^{\mathrm{HR}} \mathrm{J}^{\mathrm{R}}$ & $63.4 \pm 4.7 \mathrm{a}$ & $0.3 \pm 0.1 \mathrm{c}$ & $34.7 \pm 7.8 \mathrm{a}$ & ++ \\
\hline JT04-3 & $\mathrm{C}^{\mathrm{HR}} \mathrm{J}^{\mathrm{R}}$ & $42.6 \pm 3.8 \mathrm{c}$ & $0.5 \pm 0.1 \mathrm{~b}$ & $39.5 \pm 9.7 \mathrm{a}$ & + \\
\hline JT04-4 & $\mathrm{C}^{\mathrm{HR}} \mathrm{J}^{\mathrm{R}}$ & $56.3 \pm 3.5 b$ & $0.4 \pm 0.1 \mathrm{bc}$ & $36.8 \pm 7.2 \mathrm{a}$ & ++ \\
\hline JT04-5 & $\mathrm{C}^{\mathrm{HR}} \mathrm{J}^{\mathrm{R}}$ & $65.1 \pm 3.7 \mathrm{a}$ & $0.3 \pm 0.1 \mathrm{bc}$ & $33.6 \pm 8.8 \mathrm{a}$ & +++ \\
\hline JT04-6 & $\mathrm{C}^{\mathrm{HR}} \mathrm{J}^{\mathrm{R}}$ & $55.6 \pm 3.2 \mathrm{~b}$ & $0.2 \pm 0.1 \mathrm{c}$ & $39.6 \pm 7.9 \mathrm{a}$ & ++ \\
\hline
\end{tabular}

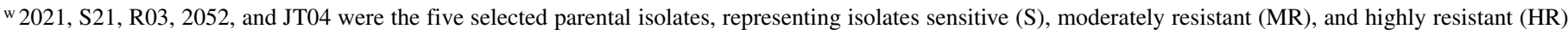
to MBC; others were the JS399-resistant mutants recovered from these five isolates which were numbered according to their parents.

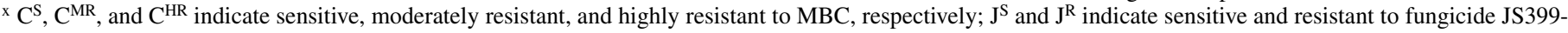
19 , respectively.

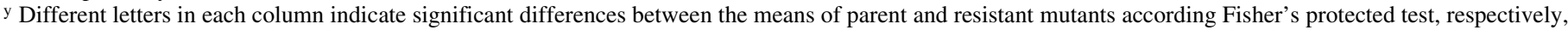
(at $P=0.05$ ) and \pm standard deviation of the mean.

$\mathrm{z}+++,++$, and + indicate perithecia covering more than two-thirds, between one-third and two-thirds, and less than one-third of the grain surface, respectively. 
main fungicide instead of carbendazim or a good companion fungicide in controlling FHB in China.

The goal of this study was to assess the potential risk in the development of double resistance to both MBC and JS399-19 in $F$. graminearum populations collected from the field. The isolates that were resistant to both MBC and JS399-19 were derived from field isolates resistant to $\mathrm{MBC}$. These isolates maintained the double resistance through eight transfers on PSA plates for 40 days and when stored on PSA slants at $4^{\circ} \mathrm{C}$ for 60 days. This stability indicated that the multiple resistance to both MBC and JS399-19 was not a temporary adaptation of the pathogen to these fungicides. None of the resistant isolates that were initially resistant to both MBC and JS399-19 became sensitive to this fungicide during the repeated subculturing. In contrast, the levels of resistance have been shown to decrease after consecutive transfers in the absence of fungicide selection pressure in other fungicidepathogen systems, such as isolates of Monilinia fructicola and Cercospora beticola, resistant to sterol demethylation inhibiting fungicides $(12,17)$.

Previous studies showed that the MBC resistance and JS399-19 resistance could not be transferred through mycelial fusion $(8,9)$. This was because the low likelihood of asexual genetic recombination in $F$. graminearum was reported in several previous studies $(2,8,9,11)$, by using genetic markers, namely nit mutants $(2,3$, $10,15,20,21,32,33)$, according to the guidelines of genetic ter- minology for plant-pathogenic fungi (30). Moreover, considering that the extensive levels of genetic diversity in $F$. graminearum have been reported by using vegetative compatibility tests as a marker $(2,3,15,20,21,23,32)$, it could be speculated, therefore, that MBC and JS399-19 resistance might not be exchanged by mycelial fusion or could be exchanged only with low chance between two compatible isolates, and that MBC-resistant isolates would hardly develop resistance to fungicide JS399-19 by mycelial fusion. However, according to a most recent study which indicated sexual recombination of MBC resistance (9), it could also be speculated, therefore, that MBC and JS399-19 resistance in $F$. graminearum might exchange through sexual recombination and this should be further confirmed.

The mycelial growth and conidial production capacity were decreased in some resistant mutants, indicating a fitness cost was associated with JS399-19-resistant phenotypes of $F$. graminearum isolates. However, most of the mutants resistant to both MBC and JS399-19 exhibited high sexual reproduction capacity and pathogenicity as their parental isolates. Nevertheless, most of these mutants possessed fitness levels comparable to their parents.

The results on the efficacy of the two fungicides for controlling FHB incited by the fungicide-resistant mutants were generally parallel to those of in vitro sensitivity tests. The MBC+JS399-19 failed to control FHB caused by the isolates resistant to both MBC and JS399-19, while the mixture was effective against the

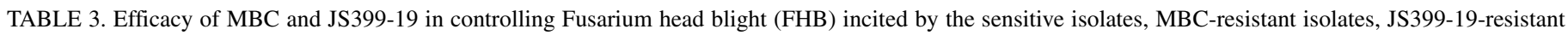
isolates, and the isolates of Fusarium graminearum resistant to both MBC and JS399-19

\begin{tabular}{|c|c|c|c|c|}
\hline Isolate $^{\mathrm{v}}$ & Resistance phenotypes $^{\mathrm{w}}$ & Treatment $^{\mathrm{x}}$ & FHB severity $(\%)$ & Efficacy $(\%)^{\mathrm{y}}$ \\
\hline \multirow[t]{4}{*}{2021} & $\mathrm{C}^{\mathrm{S} J \mathrm{~S}}$ & Nontreated & $36.55 \mathrm{a}^{\mathrm{z}}$ & $\ldots$ \\
\hline & & $\mathrm{MBC}$ & $6.53 \mathrm{~b}$ & $82.13 \mathrm{a}$ \\
\hline & & JS399-19 & $4.77 \mathrm{~b}$ & $86.95 \mathrm{a}$ \\
\hline & & MBC+JS399-19 & $4.26 \mathrm{~b}$ & $88.34 \mathrm{a}$ \\
\hline \multirow[t]{4}{*}{$2021-1$} & $\mathrm{C}^{\mathrm{S}} \mathrm{J}^{\mathrm{R}}$ & Nontreated & $37.62 \mathrm{a}$ & $\ldots$ \\
\hline & & $\mathrm{MBC}$ & $5.36 \mathrm{c}$ & $85.75 \mathrm{a}$ \\
\hline & & JS399-19 & $20.73 b$ & $44.90 \mathrm{~b}$ \\
\hline & & MBC+JS399-19 & $5.21 \mathrm{c}$ & $86.15 \mathrm{a}$ \\
\hline \multirow[t]{4}{*}{ S21 } & $\mathrm{C}^{\mathrm{S}} \mathrm{J}^{\mathrm{S}}$ & Nontreated & $37.69 \mathrm{a}$ & $\ldots$ \\
\hline & & $\mathrm{MBC}$ & $7.45 \mathrm{~b}$ & $80.23 \mathrm{a}$ \\
\hline & & JS399-19 & $5.63 \mathrm{~b}$ & $85.06 \mathrm{a}$ \\
\hline & & MBC+JS399-19 & $5.22 \mathrm{~b}$ & $86.15 \mathrm{a}$ \\
\hline \multirow[t]{4}{*}{ S21-1 } & $\mathrm{C}^{\mathrm{S}} \mathrm{J}^{\mathrm{R}}$ & Nontreated & $35.73 \mathrm{a}$ & $\ldots$ \\
\hline & & $\mathrm{MBC}$ & $7.52 \mathrm{c}$ & $78.95 \mathrm{a}$ \\
\hline & & JS399-19 & $19.63 \mathrm{~b}$ & $45.06 \mathrm{~b}$ \\
\hline & & MBC+JS399-19 & $5.34 \mathrm{c}$ & $85.05 \mathrm{a}$ \\
\hline \multirow[t]{4}{*}{ JT04 } & $\mathrm{C}^{\mathrm{HR} J \mathrm{~S}}$ & Nontreated & $37.35 \mathrm{a}$ & $\ldots$ \\
\hline & & $\mathrm{MBC}$ & $25.63 \mathrm{~b}$ & $31.38 \mathrm{~b}$ \\
\hline & & JS399-19 & $6.52 \mathrm{c}$ & $82.54 \mathrm{a}$ \\
\hline & & MBC+JS399-19 & $5.54 \mathrm{c}$ & $85.17 \mathrm{a}$ \\
\hline \multirow[t]{4}{*}{ JT04-1 } & $\mathrm{C}^{\mathrm{HR}} \mathrm{J}^{\mathrm{R}}$ & Nontreated & $38.43 \mathrm{a}$ & $\ldots$ \\
\hline & & $\mathrm{MBC}$ & $24.54 \mathrm{~b}$ & $36.14 \mathrm{a}$ \\
\hline & & JS399-19 & $26.14 b$ & $31.98 \mathrm{a}$ \\
\hline & & MBC+JS399-19 & $24.24 \mathrm{~b}$ & $36.92 \mathrm{a}$ \\
\hline \multirow[t]{4}{*}{2052} & $\mathrm{C}^{\mathrm{MRJ}} \mathrm{J}^{\mathrm{S}}$ & Nontreated & $37.68 \mathrm{a}$ & $\ldots$ \\
\hline & & $\mathrm{MBC}$ & $23.57 \mathrm{~b}$ & $37.45 \mathrm{~b}$ \\
\hline & & JS399-19 & $4.65 \mathrm{c}$ & $87.66 \mathrm{a}$ \\
\hline & & MBC+JS399-19 & $4.08 \mathrm{c}$ & $89.17 \mathrm{a}$ \\
\hline \multirow[t]{4}{*}{$2052-2$} & $\mathrm{C}^{\mathrm{MR} J \mathrm{R}}$ & Nontreated & $38.48 \mathrm{a}$ & $\ldots$ \\
\hline & & $\mathrm{MBC}$ & $29.67 \mathrm{c}$ & $22.90 \mathrm{~b}$ \\
\hline & & JS399-19 & $28.43 \mathrm{~b}$ & $26.12 \mathrm{~b}$ \\
\hline & & MBC+JS399-19 & $20.53 \mathrm{c}$ & $46.64 \mathrm{a}$ \\
\hline
\end{tabular}

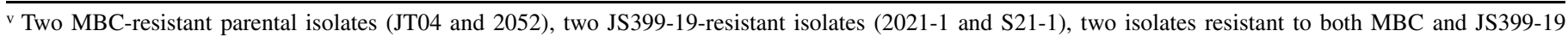
(JT04-1 and 2052-2), and two sensitive parental isolates (2021 and S21) were randomly selected for testing the efficacy of MBC and JS399-19 in controlling FHB caused by these isolates (2021-1, S21-1, JT04-1, and 2052-2 were derived from 2021, S21, JT04, and 2052, respectively).

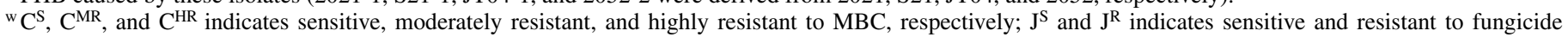
JS399-19, respectively.

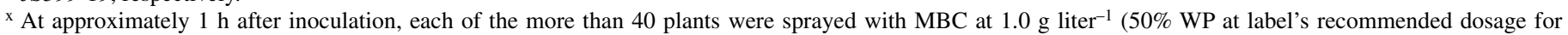
wheat), JS399-19 at $0.5 \mathrm{~g} \mathrm{liter}^{-1}\left(25 \% \mathrm{SC}\right.$ at label's recommended dosage for wheat), and MBC+JS399-19 at $1.0 \mathrm{~g}$ liter ${ }^{-1}+0.5 \mathrm{~g}$ liter ${ }^{-1}$, respectively, with a hand-held sprayer until numerous droplets were deposited onto the spikes. Spikes sprayed with water were used as the untreated control.

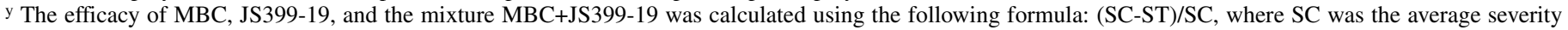
of scabbed wheat heads from more than 40 untreated control spikes and ST was that from the more than 40 fungicide-treated spikes.

${ }^{z}$ Data within columns for each isolate followed by the same letter are not significantly different according to Fisher's least significant difference test $(P=0.05)$. 
disease caused by the sensitive, the MBC-resistant, or the JS39919-resistant isolates.

In conclusion, using a mutagenesis approach, we obtained the isolates resistant to both MBC and JS399-19 which showed stable double resistance and possessed fitness levels comparable to their parents; and thus, there might be a high risk for the development of JS399-19 resistance in field isolates of $F$. graminearum resistant to $\mathrm{MBC}$ and appropriate precautions against resistance development should be taken. A previous study showed that the mixture triazoles + benzimidazoles, such as cyproconazole + MBC and tebuconazole + thiabendazole, could be effective against FHB and delay the resistance development $(16,24)$. Moreover, considering that there was no positive cross-resistance between JS399-19 and fungicides belonging to other chemical classes, such as benzimidazoles (MBC), ergosterol biosynthesis inhibitors (tebuconazole and prochloraz), and strobilurins (azoxystrobin), combining or alternating application of JS399-19 with any of these fungicides will be a valuable tool to limit fungicide resistance development (19). However, all the resistant isolates were recovered from the laboratory, which might not mean that the field MBC-sensitive and -resistant isolates would exhibit the same level of resistance to JS399-19. Therefore, a large-scale monitoring for fungicide resistance to $\mathrm{MBC}$ and this new product JS399-19 should be performed since no JS399-19 resistance in the field is available and the field JS399-19 resistance would help to clarify this point. The mode of action of the new fungicide JS399-19 is unknown and studies are required so that such knowledge can help design more effective strategies of resistance management than those presently used in China against FHB. In addition, a continuous monitoring for resistant $F$. graminearum to JS399-19 is needed since this new fungicide has been marketed and used extensively in fields of wheat and other cereals in China.

\section{ACKNOWLEDGMENTS}

This study was sponsored by (i) the State "973" Programs from the Ministry of Science and Technology of China (2006CB101907); (ii) the State "863" Programs from the Ministry of Science and Technology of China (2008AA10Z414); (iii) National Natural Science Foundation of China (30671048 and 30671384); (iv) the Key Technology R\&D program from the Ministry of Science and Technology of China (2006BAE01A0408); (v) Doctor Funding of Chinese Education Department (20050307028); and (vi) Jiangsu Provincial Program for Tackling Key Problems of Science and Technology (BG2006328).

\section{LITERATURE CITED}

1. Bai, G., and Shaner, G. 1994. Scab of wheat: Prospects for control. Plant Dis. 78:760-766.

2. Bowden, R. L., and Leslie, J. F. 1992. Nitrate non-utilizing mutants of Gibberella zeae (Fusarium graminearum) and their use in determining vegetative compatibility. Exp. Mycol. 16:308-315.

3. Bowden, R. L., and Leslie, J. F. 1994. Diversity of Gibberella zeae (Fusarium graminearum) at a small spatial scales. (Abstr.) Phytopathology 84:1140.

4. Butters, R. L., and Hollomon, D. W. 1999. Resistance to benzimidazole can be caused by changes in $\beta$-tubulin isoforms. Pestic. Sci. 55:486-503.

5. Casale, W. L., and Hart, L. P. 1988. Inhibition of 3 H-leucine incorporation by trichothecene mycotoxins in maize and wheat tissue. Phytopathology 78:1673-1677.

6. Chen, C. J., Wang, J. X., Luo, Q. Q., Yuan, S. K., and Zhou, M. G. 2007. Characterization and fitness of carbendazim-resistant strains of Fusarium graminearum (wheat scab). Pest Manag. Sci. 63:1201-1207.

7. Chen, L. F., Bai, G. H. and Desjardins, A. E. 2000. Recent advances in wheat head scab research in China. National Agricultural Library. (http://www.nal.usda.gov/pgdic/WHS/whsindex.html).

8. Chen, Y., Chen, C., Wang, J., Jin, L., and Zhou, M. 2007. Genetic study on JS399-19 resistance in hyphal fusion of Fusarium graminearum by using nitrate nonutilizing mutants as genetic markers. J. Genet. Genomics 34:469-476.

9. Chen, Y., Wang, J.-X., Zhou, M.-G., Chen, C.-J., and Yuan, S.-K. 2007. Vegetative compatibility of Fusarium graminearum isolates and genetic study on their carbendazim-resistance recombination in China. Phytopathology 97:1584-1589.

10. Correll, J. C., Harp, T. L., Guerber, J. C., Zeigler, R. S., Liu, B., and Cartwright, R. D. 2000. Characterization of Pyricularia grisea in the United States using independent genetic and molecular markers. Phytopathology 90:1396-1404.

11. Correll, J. C., Klittich, C. J. R., and Leslie, J. F. 1987. Nitrate nonutilizing mutants of Fusarium oxysporum and their use in vegetative compatibility tests. Phytopathology 77:1640-1646.

12. Cox, K. D., Bryson, P. K., and Schnabel, G. 2007. Instability of propiconazole resistance and fitness in Monilinia fructicola. Phytopathology 97:448-453.

13. Davidse, L. C., and Ishii, H. 1995. Biochemical and molecular aspects of the mechanisms of action of benzimidazoles, $\mathrm{N}$-phenylformamidoximes and the mechanism of resistance to these compounds in fungi. Pages 305322 in: Modern Selective Fungicides: Properties, Applications and Mechanisms of Action. H. Lyr, ed. Longman Scientific \& Technical, New York.

14. Forsyth, O. M., Yoshizawa, T., and Morooka, N. 1977. Emetic and refusal activity of deoxynivalenol to swine. Appl. Environ. Microbiol. 34:547552.

15. Gilbert, J., Abramson, D., McCallum, S., and Clear, R. 2001. Comparison of Canadian Fusarium graminearum isolates for aggressiveness, vegetative compatibility, and production of ergosterol and mycotoxins. Mycopathologia 153:209-215.

16. Ishii, H. 2006. Impact of fungicide resistance in plant pathogens on crop disease control and agricultural environment. JARQ 40:205-211.

17. Karaoglanidis, G. S., and Thanassoulopoulos, C. C. 2002. Phenotypic instability of Cercospora beticola Sacc. strains expressing resistance to the sterol demethylation-inhibiting fungicide flutrial after cold exposure. J. Phytopathol. 150:692-696.

18. Klittich, C. J. R., and Leslie, J. F. 1988. Nitrate reduction mutants of Fusarium moniliforme (Gibberella fujikuroi). Genetics 118:417-423.

19. Li, H. K., Diao, Y., Wang, J. X., Chen, C., Ni, J., and Zhou, M. 2008. JS399-19, a new fungicide against wheat scab. Crop Prot. 27:90-95.

20. Maria, L. R., Maria, M. R., Maria, C. F., and Sofia, C. 2006. Vegetative compatibility and mycotoxin chemotypes among Fusarium graminearum (Gibberella zeae) isolates from wheat in Argentina. Eur. J. Plant Pathol. 115:139-148.

21. McCallum, B. D., Tekauz, A., and Gilbert, J. 2001. Vegetative compatibility among Fusarium graminearum (Gibberella zeae) isolates from barley spikes in Southern Manitoba. Can. J. Plant Pathol. 23:83-87.

22. McMullen, M. P., Jones, R., and Gallenberg, D. 1997. Scab of wheat and barley: A re-emerging disease of devastating impact. Plant Dis. 81:13401348.

23. Moon, J. H., Lee, Y. H., and Lee, Y. W. 1999. Vegetative compatibility groups in Fusarium graminearum isolates from corn and barley in Korea. Plant Pathol. J. 15:53-56.

24. Pirgozliev, S. R., Edwards, S. G., Hare, M. C., and Jenkinson, P. 2003. Strategies for the control of Fusarium head blight in cereals. Eur. J. Plant Pathol. 109:731-742.

25. Proctor, R. H., Hohn, T. M., and McCormick, S. P. 1995. Reduced virulence of Gibberella zeae caused by disruption of trichothecene toxin biosynthesis gene. Mol. Plant-Microbe Interact. 8:593-601.

26. Snijders, C. H. A. 1990. Fusarium head blight and mycotoxin contamination of wheat, a review. Neth. J. Plant Pathol. 96:187-198.

27. Tomohiro, B., and Kazuhiro, S. 2000. Genetic analysis of resistance to Fusarium head blight caused by Fusarium graminearum in Chinese wheat cultivar Sumai 3 and the Japanese cultivar Saikai 165. Euphytica 113:8799.

28. Wang, J. X., and Zhou, M. G. 2002. Methods for monitoring resistance of Gibberella zeae to carbendazim. Acta Phytophylactica Sin. 29:73-77.

29. Wang, J. X., Zhou, M. G., Lu, Y. J., and Ye, Z. Y. 2002. Dynamics of resistant population of Fusarium graminearum to carbendazim and substitutable fungicide screening. J. Nanjing Agric. Univ. 25:43-47.

30. Yoder, O. C., Valent, B., and Chumley, F. 1986. Genetic nomenclature and practice for plant pathogenic fungi. Phytopathology 76:383-385.

31. Yuan, S., and Zhou, M. 2005. A major gene for resistance to carbendazim in field isolates of Gibberella zeae. Can. J. Plant Pathol. 27:58-63.

32. Zeller, K. A., Bowden, R. L., and Leslie, J. F. 2003. Diversity of epidemic populations of Gibberella zeae from small quadrats in Kansas and North Dakota. Phytopathology 93:874-880.

33. Zhang, C. Q., and Zhou, M. G. 2006. Recovery and characterization of asexual recombinants of Magnaporthe grisea. Phytoparasitica 34:54-62.

34. Zhou, M. G., and Wang, J. X. 2001. Study on sensitivity base-line of Fusarium graminearum to carbendazim and biological characters of MBC-resistant strains. Acta Phytopathol. Sin. 31:365-370.

35. Zhou, M. G., Ye, Z. Y., and Liu, J. F. 1994. Progress of fungicide resistance. J. Nanjing Agric. Univ. 17(3):33-41. 